\title{
Endurance running exercise is an effective alternative to estradiol replacement for restoring hyperglycemia through TBC1D1/GLUT4 pathway in skeletal muscle of ovariectomized rats
}

\author{
Mizuho Kawakami ${ }^{1} \cdot$ Naoko Yokota-Nakagi $^{1} \cdot$ Akira Takamata $^{1} \cdot$ Keiko Morimoto $^{1}$
}

Received: 5 March 2019 / Accepted: 20 October 2019 / Published online: 28 November 2019

(c) The Physiological Society of Japan and Springer Japan KK, part of Springer Nature 2019

\begin{abstract}
Menopause is a risk factor for impaired glucose metabolism. Alternative treatment of estrogen for postmenopausal women is required. The present study was designed to investigate the effects of 5-week endurance running exercise (Ex) by treadmill on hyperglycemia and signal pathway components mediating glucose transport in ovariectomized (OVX) placebo-treated rats, compared with 4-week 17 $\beta$-estradiol (E2) replacement or pair-feeding (PF) to the E2 group. Ex improved the hyperglycemia and insulin resistance index in OVX rats as much as E2 or PF did. However, Ex had no effect on body weight gain in the OVX rats. Moreover, Ex enhanced the levels of GLUT4 and phospho-TBC1D1 proteins in the gastrocnemius of the OVX rats, but E2 or PF did not. Instead, the E2 increased the Akt2/AS160 expression and activation in the OVX rats. This study suggests that endurance Ex training restored hyperglycemia through the TBC1D1/GLUT4 pathway in muscle by an alternative mechanism to E2 replacement.
\end{abstract}

Keywords Estradiol replacement $\cdot$ Hyperglycemia $\cdot$ Insulin resistance $\cdot$ TBC1D1/GLUT4 pathway $\cdot$ Running exercise training · Ovariectomized rat

\section{Introduction}

Postmenopausal women are at higher risk for metabolic disorders, such as metabolic syndrome and type 2 diabetes than premenopausal women $[1,2]$. Because estrogens play an important role in the control of energy homeostasis in females, estrogen deficiency in menopausal status is associated with visceral fat accumulation [3, 4], impaired glucose tolerance, and insulin resistance. Similarly, ovariectomized (OVX) rats, an animal model widely used for studying the pathology of human menopause, develop body weight, visceral fat accumulation, and impairment of wholebody glucose homeostasis [5, 6]. Recently, we found that $17 \beta$-estradiol (E2) replacement restored the impairment of insulin sensitivity by increasing the activation of the insulin signaling pathway in the gastrocnemius muscle of OVX rats

Keiko Morimoto

kmorimot@cc.nara-wu.ac.jp

1 Department of Environmental Health, Faculty of Human Life and Environment, Nara Women's University, Kita-Uoya Nishi-machi, Nara 630-8506, Japan
[7]. These findings suggest that E2 replacement restores glucose metabolism as its direct action in OVX rats. In addition, the inhibitory effect of estrogen against abdominal obesity may be partly associated with restoring the insulin sensitivity, since visceral fat accumulation contributes to glucose intolerance $[2,8]$.

Estrogen replacement in postmenopausal women is usually performed in combination with progesterone, a treatment known as hormone replacement therapy (HRT). The metabolic impact of HRT varies depending on the dose of the estrogen component, the type of progesterone, and the route of administration [10-12]. Previous studies have reported that HRT exerts a beneficial effect on the glucose metabolism [9]; however, it deteriorates insulin sensitivity, attributed to progesterone or high doses of estrogen [10-12]. Additionally, the general efficacy and safety of HRT is controversial due to the risks associated, including stroke and coronary heart disease, as well as an elevated risk of breast cancer, which were increased in the HRT trials performed by the Women's Health Initiative [13]. Therefore, it is essential to develop alternative treatments that restore the positive glucose metabolic effects of estrogen. 
Several human studies show that aerobic exercise (Ex) is insulin-sensitizing and that training is an effective substitute or adjunct for HRT $[14,15]$. As evidenced in rodent studies, Ex training initiated at the onset of OVX maintained normal skeletal muscle glucose uptake, prevented visceral adipose accretion, and improved whole-body glucose tolerance in OVX rats [16, 17]. However, to our knowledge, mechanisms underlying the abilities of Ex training to improve glucose metabolism under reduced estrogen function are not fully understood.

Skeletal muscle is the major tissue responsible for uptake of glucose from the blood, accounting for $70-85 \%$ of wholebody glucose disposal [18]. Insulin and Ex/muscle contraction are two widely studied physiological stimuli that increase glucose uptake via the activation of intracellular signaling cascades [19-21]. The signaling mechanism by which insulin stimulates muscle glucose uptake is relatively well known, and involves phosphorylation of protein kinase B (Akt) and the Rab-GTPase activating protein (Rabs), an Akt substrate of $160 \mathrm{kDa}$ (AS160) [22, 23]. In contrast, the signaling mechanism by which Ex acts is not fully understood, although studies have shown that activation of AMP-activated protein kinase (AMPK), an energy sensing kinase, is positively correlated with increases in muscle glucose uptake [24]. Furthermore, the downstream regulators of AMPK are still debated, while AS160 or TBC1 (Tre2, BUB2, CDC16) domain family member 1 (TBC1D1), another Rabs of AS160 (also known as TBC1D4), is reported as a glucose uptake regulator in Ex/muscle contraction $[19,21,25]$.

It is important to define the differences in molecular mechanism underlying beneficial effects of Ex training on glucose uptake in muscle of OVX rats compared with E2 replacement, whereby Ex is a critical alternative to estrogen replacement $[14,16]$. Recently, several researchers have reported the effects of Ex training on glucose transporter 4 (GLUT4), Akt protein, or mRNA level in OVX rats [17, 26, 27], but those findings were inconsistent. In this study, we focused on the effects of Ex training on signal pathway components that mediate glucose uptake in skeletal muscle and adipose tissues of OVX rats, because our previous study showed that beneficial effects of E2 replacement on insulin sensitivity were mediated by enhancing activation of the Akt2/AS160 pathway in the gastrocnemius muscle, but not in liver [7].

In addition, whether estrogen reduction in the menopausal phase directly impairs the glucose uptake mechanism [28, 29] remains unclear, or whether estrogen deficiency-induced hyperphagia induces visceral fat accumulation, which promotes insulin resistance resulting in the impairment of glucose uptake as an indirect result of estrogen deficiency [30]. A previous study reported that pair-feeding (PF) with shamoperated female rats failed to improve insulin action at the whole-body or skeletal muscle level in OVX rats, suggesting ovarian hormone deprivation to be involved in the progression of insulin resistance as a direct cause [31]. Therefore, as per the second aim of this study, we also examined the effects of PF on plasma glucose levels and the signaling pathway components that mediate glucose transport in OVX rats fed with the same diet as the E2-replaced OVX rats. This experiment may give an answer to above-mentioned question whether estrogen directly restores glucose metabolism, or whether estrogen-induced anorexia and following leanness prevents deterioration of it. The present study may give first data simultaneously showing the effects of Ex training, E2 replacement, and PF on insulin-dependent or independent signaling pathways in muscle or adipose tissue of OVX rats.

This study was designed to test an initial hypothesis, that is whether Ex training in the form of endurance running improves hyperglycemia and the insulin resistance index in the basic condition without muscle contraction through the AMPK-TBC1D1/GLUT4 pathway, which is different from the pathway activated by $\mathrm{E} 2$ replacement in skeletal muscle of OVX rats. Furthermore, the second hypothesis is that is whether E2 directly restores glucose metabolism, or whether E2-induced anorexia and following leanness prevents deterioration of it in OVX rats.

\section{Materials and methods}

\section{Animals}

The Nara Women's University Committee on Animal Experiments approved the experimental protocol. In total, 24 female Wistar rats were used in this study. The rats were housed in standard rat cages (length: $40 \mathrm{~cm}$, width: $25 \mathrm{~cm}$, and depth: $25 \mathrm{~cm}$ ) under controlled temperature and light conditions $\left(26 \pm 1^{\circ} \mathrm{C}\right.$, a 12 :12-h light-dark cycle, with lights on at 6:00 a.m.). Tap water and rodent chow (Oriental Yeast, Tokyo, Japan) were provided ad libitum.

\section{Preparation for experiments}

\section{Ovariectomy and E2 (or placebo) replacement}

Nine-week-old female rats were ovariectomized, followed by E2 or placebo (Pla) replacement as previously described [7, $32,33]$. In brief, after a 4-week-recovery period from OVX, the rats aged 13 weeks were assigned randomly to either the $\mathrm{Pla}(n=18)$ - or the E2 ( $n=6)$-treated group, and were subcutaneously implanted with either E2 (1.5 mg/60-day release) or Pla pellets (Innovative Research of America, Sarasota, FL, USA). The Pla group rats were divided into control (Pla; $n=6), \mathrm{PF}(\mathrm{Pla} / \mathrm{PF} ; n=6)$, and $\mathrm{Ex}(\mathrm{Pla} / \mathrm{Ex} ; n=6)$ groups. 


\section{Experimental protocols}

\section{PF study}

Two days after Pla replacement, the Pla/PF group was pairfed to the E2 group, i.e., given the average food intake of the E2 group in the previous day from 13 to 17 weeks of age. Food intake and body weight were monitored daily.

\section{Endurance running Ex training}

Before the Ex training protocol, the $\mathrm{Pla} / \mathrm{Ex}$ group rats were familiarized with Ex by running at $10 \mathrm{~m} / \mathrm{min}$ for $30 \mathrm{~min} /$ day on a custom-built, five-lane motorized rodent treadmill (KN-73, Natume, Tokyo, Japan) in the hours before dark for 2 weeks from 10 to 12 weeks of age, during which the rats had the intensity of Ex gradually increased. From 12 to 17 weeks of age, the rats ran $17 \mathrm{~m} / \mathrm{min}$ of treadmill running for $60 \mathrm{~min} /$ day, 5 day/week for 5 weeks. The intensity of the running Ex may be moderate, as previous researchers have estimated that running at $28 \mathrm{~m} / \mathrm{min}$ as high intensity or $8 \mathrm{~m} /$ min as low intensity elicited $\sim 75 \%$ or $\sim 45 \%$ of maximal $\mathrm{O}_{2}$ uptake in female rats $[34,35]$.

\section{Sampling for estimation of plasma glucose, insulin, and signaling pathway}

All the rats fasted for $16 \mathrm{~h}$ before blood and tissue sampling, with free access to water. On the day of sampling, after the rats were deeply anesthetized by a pentobarbital sodium (45 mg/kg body weight) [36], blood samples were collected from cardiac puncture in the four groups. After euthanasia, the gastrocnemius muscles and mesenteric adipose tissues were excised and immediately frozen in liquid nitrogen, then stored at $-50{ }^{\circ} \mathrm{C}$ until further processing of Western blotting. Parts of these tissues were stored in RNA stabilization solution, until RT-qPCR analysis for AS160 and GLUT4 mRNAs was performed. The wet weights of the intra-abdominal (mesenteric, kidney-genital, and retroperitoneal) and subcutaneous (inguinal) adipose tissues were measured. The total visceral fat weight was calculated by the sum of the intra-abdominal fat weights.

\section{Analytical methods for plasma glucose, insulin, and E2}

The plasma glucose concentration was measured by a glucose oxidase method using a glucose assay kit (Wako Pure Chemical Industries, Osaka, Japan). Plasma insulin concentration was determined by the use of a rat insulin ELISA kit (FUJIFILM Wako Shibayagi, Gunma, Japan). Using these variables, insulin resistance was assessed by a homeostasis model assessment of the insulin resistance index (HOMAIR), calculated using the following formula [37-39]:
HOMA-IR = fasting glucose concentration $(\mathrm{mmol} / \mathrm{l})$ $\times$ fasting insulin concentration $(\mu \mathrm{IU} / \mathrm{ml}) / 22.5$

The E2 concentrations were measured commercially by an electro-chemiluminescence immunoassay (SRL Co, Nara, Japan).

\section{Immunoblotting}

Isolated muscle and mesenteric adipose tissue were immediately homogenized in homogenization buffer $[320 \mathrm{mM}$ sucrose; $10 \mathrm{mM}$ Tris. $\mathrm{HCl}, \mathrm{pH}$ 7.4; $1 \mathrm{mM}$ EGTA; $10 \mathrm{mM}$ $\beta$-mercaptoethanol; $50 \mathrm{mM} \mathrm{NaF} ; 10 \mathrm{mM} \mathrm{Na}_{3} \mathrm{VO}_{4} ; 9$ tablets of cOmplete EDTA-free protease inhibitor cocktail containing $0.2 \mathrm{mM}$ PMSF, $20 \mu \mathrm{M}$ leupeptin, and $0.15 \mu \mathrm{M}$ pepstatin (Roche, Mannheim, Germany); 1\% TritonX-100], as described previously [7]. The homogenates were centrifuged at $15,000 \mathrm{~g}$ for $30 \mathrm{~min}$ at $4{ }^{\circ} \mathrm{C}$. SDS samples containing equal amounts of protein were separated by SDS-PAGE on $10 \%$ polyacrylamide gels, and immunoblotted using a PVDF membrane (GE Healthcare, Buckinghamshire, UK) with the following antibodies: antibodies for Akt and phospho (p)-Akt Ser ${ }^{473}$, p-Akt Thr ${ }^{308}$, Akt2, p-Akt2 $\operatorname{Ser}^{474}$, AMPK $\alpha$, p-AMPK $\alpha \mathrm{Thr}^{172}$, and p-AS160 $\mathrm{Thr}^{642}$ were from Cell Signaling Technology (Danvers, MA, USA). The AS160 and p-TBC1D1 $\mathrm{Ser}^{237}$ antibody were from MILLIPORE (Temecula, CA, USA), and GLUT4, TBC1D1, and Tubulin antibody from Abcam (Cambridge, MA, USA). Goat anti-rabbit horseradish peroxidase-conjugated secondary antibody was obtained from Promega (Madison, WI, USA). The enhanced chemiluminescence (ECL, GE Healthcare Life Sciences, Buckinghamshire, UK) system was used for protein detection. Imaging and densitometry were performed using the imaging system Ez-Capture (ATTO, Tokyo, Japan) and image processing program CS Analyzer (ATTO, Tokyo, Japan).

\section{RNA isolation and RT-qPCR}

Total RNA was extracted using the TRI Reagent Solution (Ambion, Austin, TX, USA) according to the manufacturer's protocol. The amount of total RNA extracted was determined, and its purity (absorption ratio of optical density $260 \mathrm{~nm}$ and $280 \mathrm{~nm}>1.9$ ) was verified spectrophotometrically using a Nanodrop 2000 (Thermo Fisher Scientific, Waltham, MA, USA). The cDNA was synthesized using the High-Capacity RNA-to-cDNA kit (Applied Biosystems, Waltham, MA, USA). RT-qPCR was performed using a StepOne Software v2.1 system (Applied Biosystems). The commercially available TaqMan Gene Expression Assay (Applied Biosystems) for AS160 (Rn01468356_m1), GLUT4 (Rn00562597_m1), and $\beta$-2M (Rn00560856_m1) 

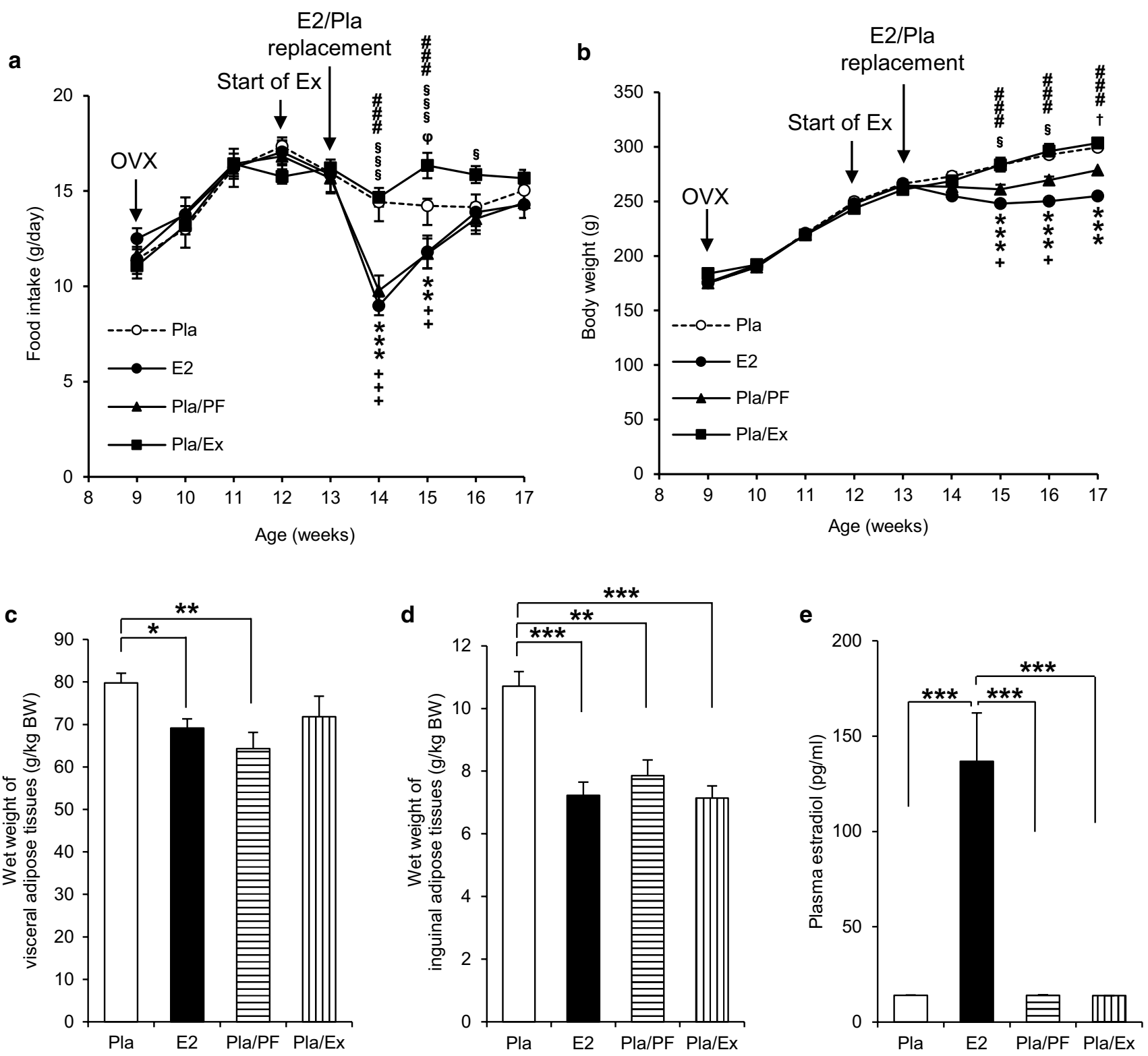

Fig. 1 Characterization of rats studied. Data are expressed as means \pm SE. Line graphs represent course of change in mean food intake per day (a) and body weight (b) in the placebo (Pla, $n=6$ )-, the $17 \beta$-estradiol (E2, $n=6)$-treated, the placebo/pair-feeding ( $\mathrm{Pla} /$ $\mathrm{PF}, n=6)$, and the placebo/exercise ( $\mathrm{Pla} / \mathrm{Ex}, n=6)$ groups. Twoway repeated-measures ANOVA revealed significant differences in food intake and body weight between the four groups. $* * P<0.01$, ${ }^{* * *} P<0.001$ : E2 vs. Pla. ${ }^{+} P<0.05,{ }^{++} P<0.01,{ }^{+++} P<0.001$ : $\mathrm{Pla} / \mathrm{PF}$ vs. Pla. ${ }^{\varphi} P<0.05$ : $\mathrm{Pla} / \mathrm{Ex}$ vs. $\mathrm{Pla} .{ }^{\dagger} P<0.05$ : $\mathrm{Pla} / \mathrm{PF}$ vs. E2. ${ }^{\# \#} P<0.001$ : $\mathrm{Pla} / \mathrm{Ex}$ vs. E2. ${ }^{\S} P<0.05$ : $\mathrm{Pla} / \mathrm{Ex}$ vs. $\mathrm{Pla} / \mathrm{PF}$. There was an interaction of time and group effects in food intake $\left(P_{\text {TimexGroup }}<0.05\right.$ : E2 vs. Pla or Pla/Ex, Pla/Ex vs. Pla) and body weight $\left(P_{\text {Time } \times \text { Group }}<0.05\right.$ : E2 vs. $\mathrm{Pla} / \mathrm{PF}$ or $\mathrm{Pla} / \mathrm{Ex}, P_{\text {TimexGroup }}<0.01$,

were used in this study. For the analysis, gene expression levels of AS160 were normalized using $\beta-2 \mathrm{M}$ as a housekeeping gene, and expressed with respect to the average
E2 vs. Pla, Pla/PF vs. Pla or $\mathrm{Pla} / \mathrm{Ex}$ ). Bar graphs represent wet weights of visceral (the sum of weights of the mesenteric, kidneygenital, and retroperitoneal adipose tissues) (c), inguinal (d) adipose tissues per body weights, and plasma E2 concentration (e) in the Pla $(n=6)-$, the $\mathrm{E} 2 \quad(n=6)$-treated, the Pla/PF $(n=6)$, and the $\mathrm{Pla} / \mathrm{Ex}$ $(n=6)$ groups at 17 weeks of age. One-way ANOVA followed by a post hoc Tukey's HSD test revealed differences in wet weights of the visceral adipose tissues per body weights between the Pla and E2 or $\mathrm{Pla} / \mathrm{PF}$ groups $(* * * P<0.001)$, and inguinal adipose tissues between the Pla and every other group $(* * * P<0.001)$. There is a difference in plasma E2 concentration between the E2 and every other group $(* * * P<0.001)$. OVX, ovariectomy. $B W$ body weight

value for the Pla group. All reactions were performed in duplicate. The thermal cycling conditions were as follows: $95^{\circ} \mathrm{C}$ for $20 \mathrm{~s}$, followed by 40 cycles at $95{ }^{\circ} \mathrm{C}$ for $1 \mathrm{~s}$ and 
Fig. 2 Plasma concentrations of glucose $(\mathrm{mmol} / \mathrm{l})(\mathbf{a})$, insulin $(\mu \mathrm{IU} / \mathrm{ml})(\mathbf{b})$, and homeostasis model assessment of insulin resistance (HOMA-IR) index (c) in the placebo (Pla, $n=6$ )-, the $17 \beta$-estradiol (E2, $n=6)$-treated, the placebo/pairfeeding (Pla/PF, $n=6)$, and the placebo/exercise (Pla/Ex, $n=6)$ groups. Data are expressed as means \pm SE and were analyzed by one-way ANOVA. This was followed by a post hoc Tukey's HSD test. $* P<0.05$, $* * P<0.01$, and $* * * P<0.001$, differences between the Pla and every other group
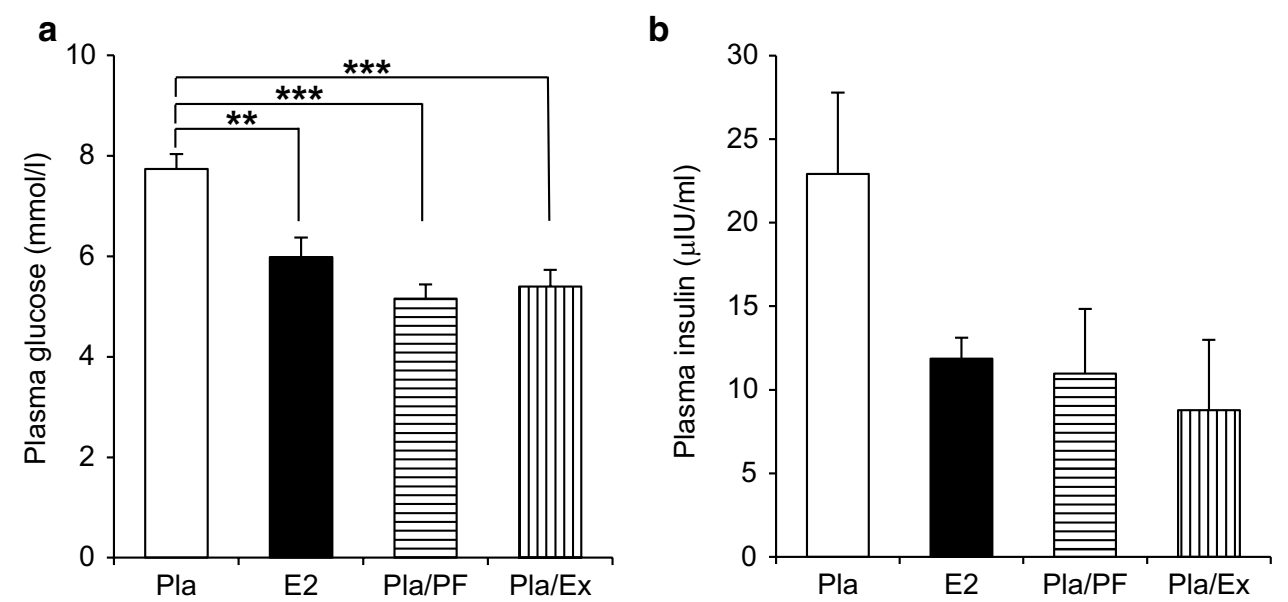

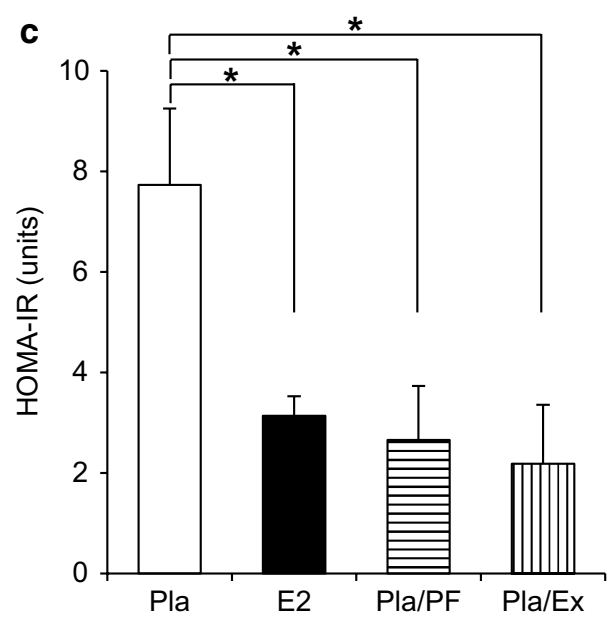

$60{ }^{\circ} \mathrm{C}$ for $20 \mathrm{~s}$. No amplification of fragments occurred in the control samples without reverse transcriptase. The mRNA quantity was calculated using the $\Delta \Delta C_{\mathrm{t}}$ (comparative $C_{\mathrm{t}}$ ) method under the assumption that primer efficiencies were relatively similar.

\section{Statistical analysis}

All values were expressed as means \pm SE. Two-way repeated-measures ANOVA for each pair-wise comparison among four groups was used to analyze the effects of $\mathrm{E} 2, \mathrm{PF}$, and Ex on body weight and food intake. One-way ANOVA was used for the comparison of the adipose tissue weight, plasma E2 and glucose concentrations, insulin concentrations, HOMA-IR, and signaling protein and mRNA levels among the four groups, and was followed by a post hoc Tukey's HSD test. We considered a value of $P<0.05$ to be statistically significant.

\section{Results}

\section{Characterization of rats studied}

As shown in Fig. 1a, food intake in the E2 group was markedly decreased at 14 and 15 weeks of age, 1-2 weeks after E2 pellet implantation, compared with that at 13 weeks $(P<0.001)$ or the Pla group $(P<0.001$ and $P<0.01$, respectively). After that, the intake in the E2 groups came to be similar to the Pla group at 16 weeks of age. In contrast, food intake in the Pla/Ex group was increased at 15 weeks of age compared with 14 weeks $(P<0.05)$, and returned to the same level as the Pla group.

The body weight in the E2 group was significantly lighter than that in the Pla group at 15-17 weeks of age (Fig. 1b). In contrast, the $\mathrm{Pla} / \mathrm{PF}$ group showed heavier body weight than the E2 group, resulting in a significant difference in the time course of body weight between the $\mathrm{E} 2$ and Pla/PF groups (interaction: $P<0.05$ ), though they were still lighter than those in the Pla group. In addition, body weights in the 
a
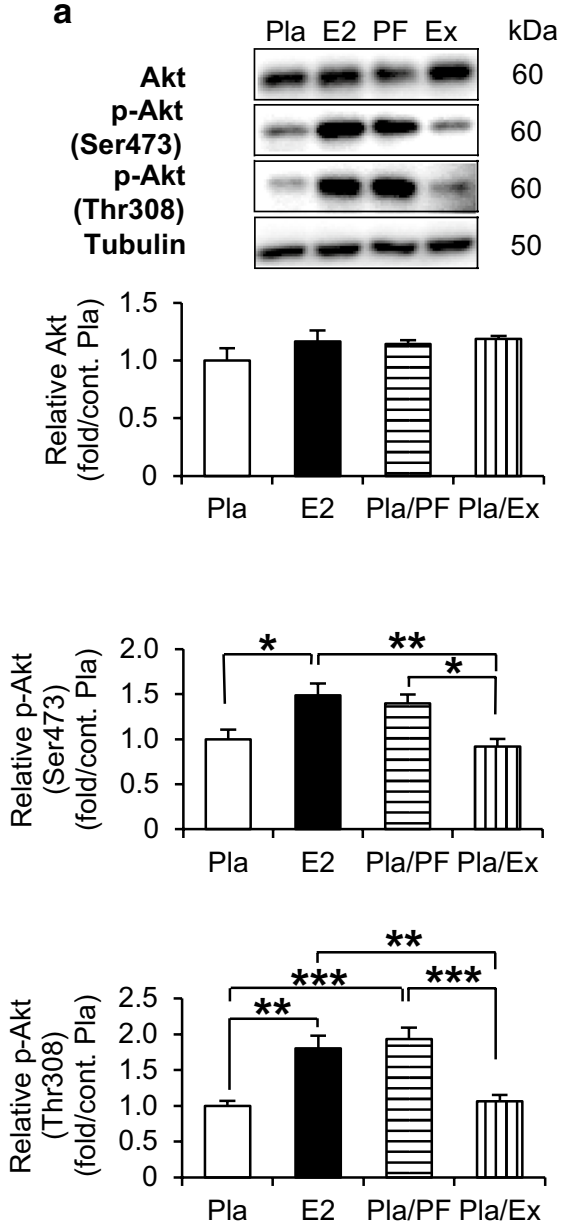

d
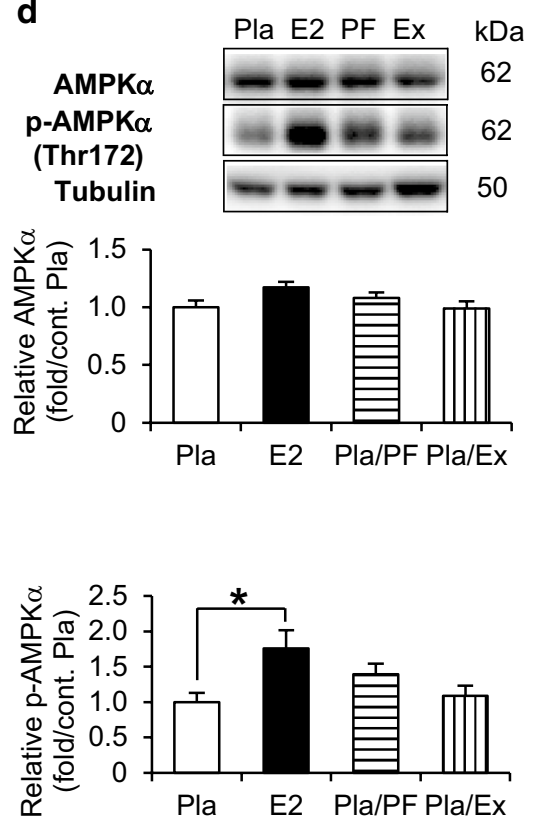

b
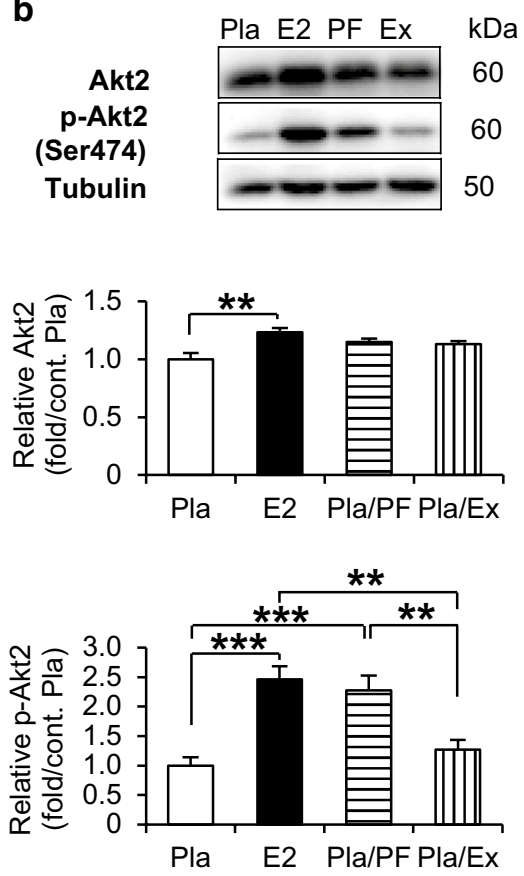

e
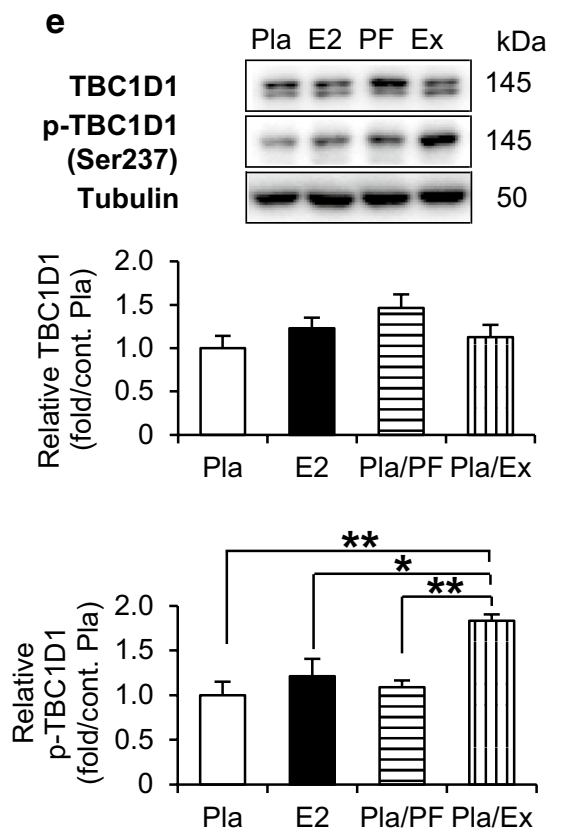

C

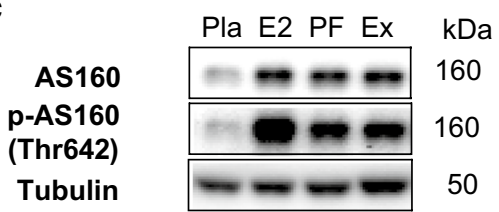

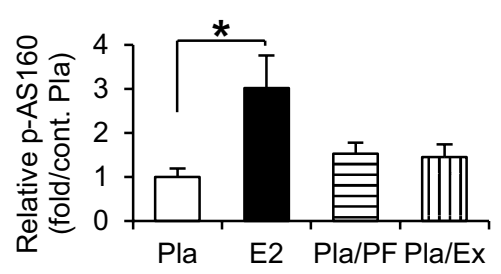

f
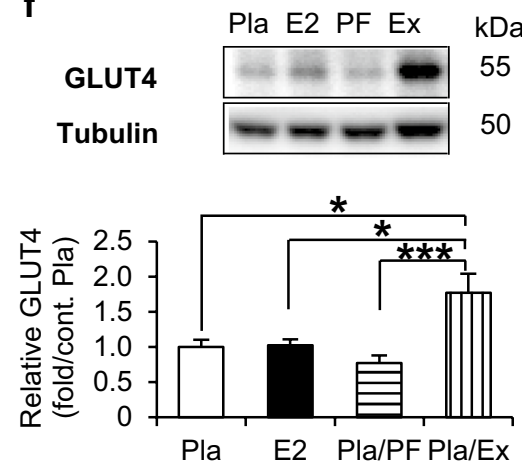
4Fig. 3 Representative blots and relative values of protein kinase B (Akt) and phospho (p)-Akt Ser ${ }^{473}$, and p-Akt $\mathrm{Thr}^{308}$ (a), Akt2, and p-Akt2 $\operatorname{Ser}^{474}$ (b), Akt substrate of $160 \mathrm{kDa}(\mathrm{AS} 160)$ and p-AS160 $\mathrm{Thr}^{642}$ (c), AMPK $\alpha$ and p-AMPK $\alpha \mathrm{Thr}^{172}$ (d), TBC1D1 and p-TBC1D1 $\operatorname{Ser}^{237}(\mathbf{e})$, and GLUT4 (f) in the gastrocnemius of rats in the placebo (Pla, $n=6)$-, the $17 \beta$-estradiol (E2, $n=6)$-treated, the placebo/pair-feeding (Pla/PF, $n=6)$, and the placebo/exercise (Pla/Ex, $n=6)$ groups. Data are expressed as means $\pm \mathrm{SE}$ and were analyzed by one-way ANOVA. This was followed by a post hoc Tukey's HSD test. $* P<0.05, * * P<0.01$, and $* * * P<0.001$, differences between the two groups

$\mathrm{Pla} / \mathrm{Ex}$ group were similar to the Pla group, but heavier than both the $\mathrm{E} 2$ and $\mathrm{Pla} / \mathrm{PF}$ groups (Fig. 1b).

The wet weights of total visceral (the sum of mesenteric, kidney-genital, and retroperitoneal) adipose tissues per body weights were significantly lighter in the E2 and $\mathrm{Pla} / \mathrm{PF}$ groups than in the Pla group (Fig. 1c). The weights of inguinal subcutaneous adipose tissues per body weights were significantly lighter in the E2, Pla/PF, and Pla/Ex groups than the Pla group (Fig. 1d). Plasma E2 concentrations were significantly higher in the E2 group than in the other Pla groups (Fig. 1e).

\section{Effects of E2, PF, and Ex on plasma glucose, insulin, and HOMA-IR}

Fasting plasma glucose concentration was significantly lower in the $\mathrm{E} 2, \mathrm{Pla} / \mathrm{PF}$, and $\mathrm{Pla} / \mathrm{Ex}$ groups than in the Pla group (Fig. 2a). In contrast, there was no significant difference in fasting plasma insulin among the Pla, E2, Pla/ $\mathrm{PF}$, and $\mathrm{Pla} /$ Ex groups (Fig. 2b). HOMA-IR indices were significantly lower in the $\mathrm{E} 2, \mathrm{Pla} / \mathrm{PF}$, and $\mathrm{Pla} / \mathrm{Ex}$ groups than in the Pla group (Fig. 2c).

\section{Effects of E2, PF, and Ex on insulin signaling and AMPK pathway in basic condition}

To reveal the molecular mechanism accounting for the effects of E2, PF, and Ex on plasma glucose and insulin, we investigated signaling pathway components mediating glucose transport, the Akt/AS160, and AMPK/TBC1D1 pathways, as well as GLUT4, in the gastrocnemius muscle (Fig. 3) and mesenteric adipose tissue (Fig. 4).

The quantity of Akt protein in the muscle was similar between the four groups (Fig. 3a). The relative levels of p-Akt $\mathrm{Ser}^{473}$ and p-Akt $\mathrm{Thr}^{308}$ were significantly higher in the E2 group than those in the Pla and Pla/Ex groups, but were not different between the Pla and the Pla/Ex groups. In addition, p-Akt $\mathrm{Thr}^{308}$ was higher in the Pla/PF group than the Pla and Pla/Ex groups. Figure $3 \mathrm{~b}$ shows that Akt2 and p-Akt $2 \mathrm{Ser}^{474}$ protein levels in the muscle were increased in E2 group compared to the Pla group $(P<0.01$ and $P<0.001$, respectively). In contrast, $\mathrm{PF}$ increased only p-Akt2 $\mathrm{Ser}^{474}$
$(P<0.001)$, but Ex had no effects on Akt2 and p-Akt2 Ser ${ }^{474}$. Furthermore, Fig. 3c shows that AS160 and p-AS160 Thr ${ }^{642}$ protein levels were increased in the E2 group compared with the $\mathrm{Pla}, \mathrm{Pla} / \mathrm{PF}$, and $\mathrm{Pla} / \mathrm{Ex}$ groups, and compared with the Pla group, respectively. Moreover, p-AMPK $\alpha \mathrm{Thr}^{172}$ in the muscle was increased in the E2 group compared to the Pla group, with no change in the protein level (Fig. 3d). Interestingly, p-TBC1D1 $\mathrm{Ser}^{237}$ in the Pla-Ex group was higher than in the Pla, E2, and Pla/PF groups, with no differences in TBC1D1 protein levels among the four groups (Fig. 3e). In addition, GLUT4 protein level was significantly higher in the Pla/Ex group than in any other group (Fig. 3f).

In the mesenteric adipose tissue, the amounts of Akt and Akt2 proteins, as well as their phosphorylated protein levels, were similar among the four groups (Fig. 4a, b). AS160 and p-AS160 Thr ${ }^{642}$ protein levels were increased in the $\mathrm{E} 2$ group compared with the Pla and Pla/Ex groups (Fig. 4c). The p-AMPK $\alpha \mathrm{Thr}^{172}$ levels were higher in the $\mathrm{E} 2, \mathrm{Pla} / \mathrm{PF}$, and $\mathrm{Pla} / \mathrm{Ex}$ groups than in the Pla group, with no differences in AMPK $\alpha$ protein levels among the four groups (Fig. 4d). In contrast, TBC1D1 and p-TBC1D1 were not different among the four groups (Fig. 4e). GLUT4 was not detected in the mesenteric adipose tissue of any group.

\section{AS160 and GLUT4 mRNA levels in the gastrocnemius muscle and mesenteric adipose tissue}

The levels of AS160 and GLUT4 mRNAs in the gastrocnemius muscle or mesenteric adipose tissue of the four groups were determined by RT-qPCR. As shown in Fig. 5a, the relative level of AS160 mRNA in the muscle was higher in the E2 group than those in the Pla $(P<0.01), \mathrm{Pla} / \mathrm{PF}$, and $\mathrm{Pla} /$ Ex groups. In contrast, the relative GLUT4 mRNA in the muscle and AS160 mRNA levels in the mesenteric adipose tissues were similar among the four groups (Fig. 5b, c).

\section{Discussion}

The present study demonstrated that endurance running Ex training improved hyperglycemia by the activation of the TBC1D1/GLUT4 pathway in the muscle of OVX rats. The mechanism varied from that of E2 replacement, which restored hyperglycemia via the activated Akt2/AS160 pathway in the muscle, or from that of $\mathrm{PF}$ of the $\mathrm{E} 2$ replaced rats.

Endurance Ex training did not affect body weight gain in the OVX rats despite a decrease in inguinal fat accumulation. It is likely that Ex training might increase lean body mass instead of subcutaneous adipose tissues. In contrast, the E2 replacement suppressed body weight compared with the OVX rats by reducing both visceral and inguinal fat accumulations. In addition, PF partially compensated the 
a
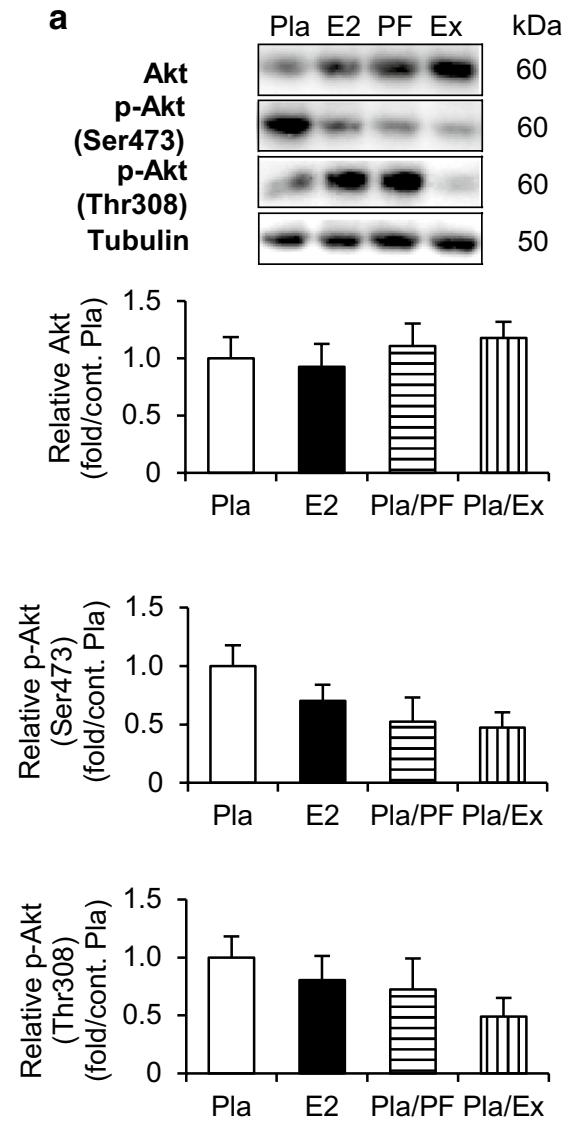

d
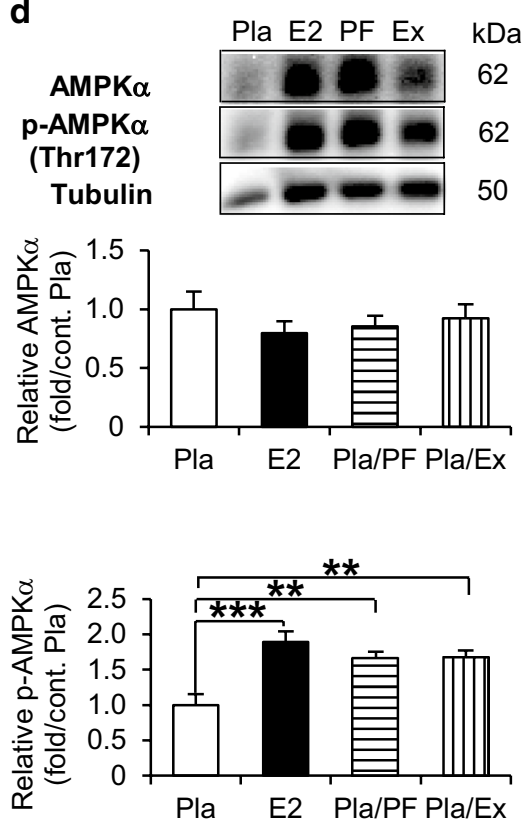

b

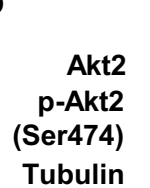

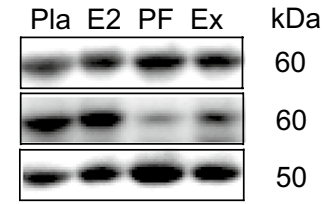
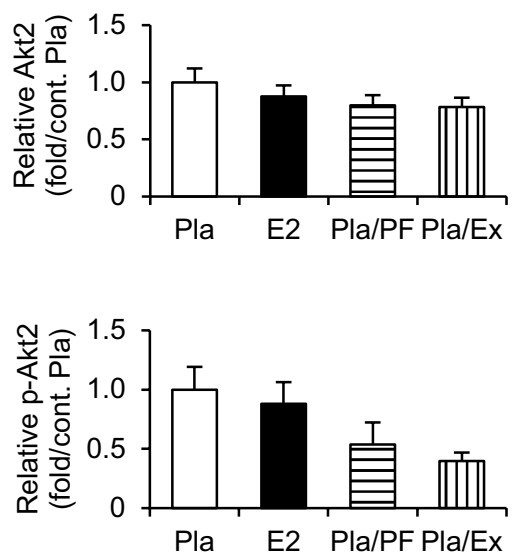

C
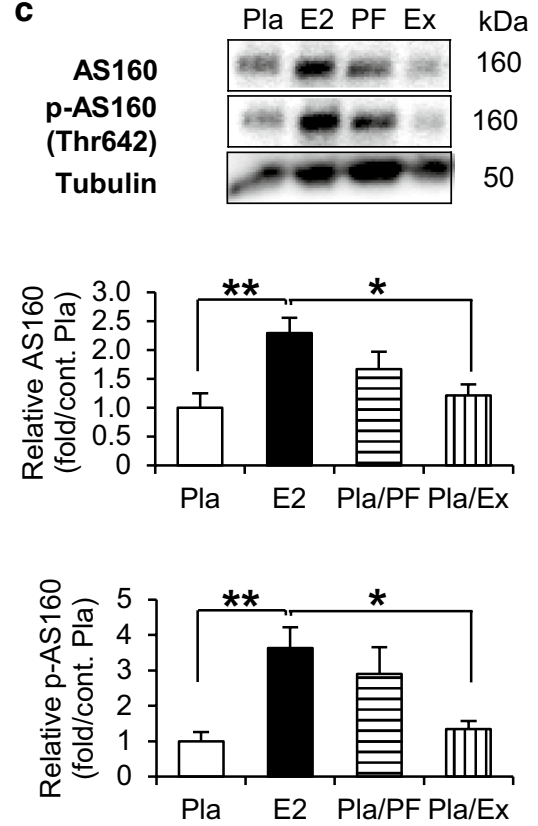

e
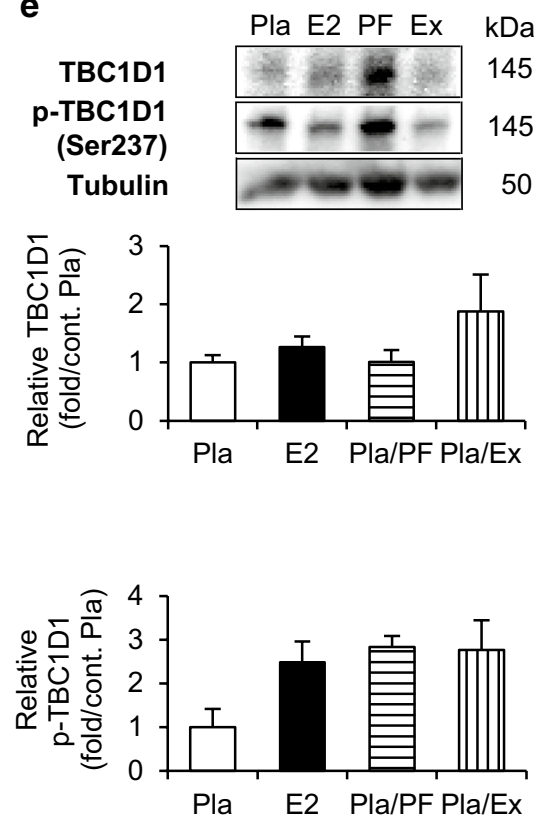

Fig. 4 Representative blots and relative values of protein kinase B (Akt) and phospho (p)-Akt $\mathrm{Ser}^{473}$, and p-Akt $\mathrm{Thr}^{308}$ (a), Akt2 and p-Akt2 $\operatorname{Ser}^{474}$ (b), Akt substrate of $160 \mathrm{kDa}$ (AS160) and p-AS160 $\mathrm{Thr}^{642}$ (c), AMPK $\alpha$ and p-AMPK $\alpha \mathrm{Thr}^{172}$ (d), and TBC1D1 and p-TBC1D1 $\operatorname{Ser}^{237}$ (e) in the mesenteric adipose tissues of rats in the placebo (Pla, $n=6$ )-, the $17 \beta$-estradiol (E2, $n=6$ )-treated, the pla- cebo/pair-feeding ( $\mathrm{Pla} / \mathrm{PF}, n=6)$, and the placebo/exercise (Pla/Ex, $n=6)$ groups. Data are expressed as means \pm SE and were analyzed by one-way ANOVA. This was followed by a post hoc Tukey's HSD test. $* P<0.05$, $* * P<0.01$, and $* * * P<0.001$, differences between the two groups 
suppressive effect of E2 replacement on body weight gain in the OVX rats. In our previous study using a radiotelemetry system $[32,33]$, we confirmed that the 24-h locomotor activities of freely moving rats did not differ between Pla and E2 groups (24-h average: $2.40 \pm 0.39$ counts/min vs. $2.31 \pm 0.14$ counts/min in Pla and E2 groups, respectively). Further study is required to confirm the locomotor activity of rats in the PF or Ex group. Therefore, E2 replacement may suppress body weight gain not only by reducing energy intake, but also by enhancing the energy metabolism in OVX rats. These findings are at least partially consistent with several previous studies that demonstrated a direct effect of estrogen on the energy metabolism [40-42], and with some other studies, showing that the anorexigenic effect of estrogen was a major contributor to the suppression of adiposity and body weight $[43,44]$.

The present study shows that 4-week E2 replacement or 5-week Ex training in OVX rats reduced the basal level of plasma glucose without affecting plasma insulin levels. This result was inconsistent with previously reported findings that resting basal levels of both insulin and glucose were not different among OVX, E2-treated, and endurance Ex-trained OVX rats [17, 27]. In contrast, our previous study using male rats showed that the resting levels of blood glucose in Ex-trained rats were lower than those in untrained rats [45]. These discrepancies may depend on experimental conditions: notably, intensity and duration of Ex training, conditions for blood sampling, dose of estrogen replacement, or period after OVX. In our study design, an intensity of the Ex training on a treadmill $(17 \mathrm{~m} / \mathrm{min})$ might be moderate, because previous investigations have chosen low-intensity $(8 \mathrm{~m} / \mathrm{min})$ or high-intensity $(28 \mathrm{~m} / \mathrm{min})$ treadmill running to train female Sprague-Dawley rats [35] based on the finding that a running speed at $8 \mathrm{~m} / \mathrm{min}$ and $28 \mathrm{~m} / \mathrm{min}$ in female rats elicited $\sim 45 \%$ and $\sim 75 \%$ of maximal $\mathrm{O}_{2}$ uptake, respectively [34]. Additionally, in this study, blood was collected under 16-h fasting conditions from cardiac puncture 4 weeks after E2 replacement and 5 weeks after Ex training started in the OVX rats. Therefore, the duration of each intervention and the moderate intensity of Ex training may be appropriate to cause differences in basal plasma glucose levels.

In our study design, a 3-week-recovery duration was required after OVX and before the Ex training to achieve stable low levels of plasma E2. This was needed to evaluate the effects of Ex training in the OVX rats characterized by low plasma E2 levels, similar to postmenopausal women. Therefore, the present results suggest that Ex training can restore the developed hyperglycemia in the OVX rats. These findings showed the effectiveness of Ex training as an alternative treatment for postmenopausal women. In contrast, rats in the E2 group were administered E2 replacement for 4 weeks after a 4-week-recovery period from OVX to ensure that the plasma levels were stabilized at moderately high levels of E2 $(136.9 \pm 25.4 \mathrm{pg} / \mathrm{ml})$, as seen in a postmenopausal model replaced by E2, which were within the physiological range for intact female rats in proestrus reported in previous studies $[46,47]$.

To assess the anorexigenic effect of E2 replacement on glucose homeostasis, we included a Pla/PF group of rats in our experiments. Food restriction by $\mathrm{PF}$ in the $\mathrm{Pla} / \mathrm{PF}$ group ameliorated hyperglycemia in the OVX rats, but failed to mimic the effects of E2 replacement on signal pathway components mediating glucose transport. E2 increased Akt2 and AS160 protein levels, their phosphorylation, and AS160 mRNA level, but PF increased only phospho-Akt2. These findings show that the effects of $\mathrm{E} 2$ replacement on the transcriptional upregulation of AS160 were not mediated by PF-induced metabolic changes in OVX rats, suggesting direct E2 action, most likely via the estrogen receptor. On the other hand, a previous study reported that even in obese male Zucker rats, food restriction throughout the first year of life did not alter the development of hyperplastic obesity and insulin resistance [48].

Our study did not determine how OVX induces glucose intolerance, as our experiment did not include a group of sham-operated rats. However, the fact that E2 replacement restored the Akt2/AS160 pathway suggests that OVX impairs the signal pathway that mediates glucose transport. Unlike E2 replacement, Ex had no activating effect on the Akt/AS160 pathway in the OVX rats. Alternatively, the present study revealed that Ex training enhanced the TBC1D1/GLUT4 pathway in the muscle of the OVX rats, and improved hyperglycemia similar to E2 replacement.

Recent studies have reported the effects of Ex training on the signal pathway components, especially GLUT4 in OVX rats $[17,26,27]$. These findings were inconsistent, because it was reported that chronic Ex increased the GLUT4 protein levels of skeletal muscles from OVX rats [17], that Ex reduced the mRNA expression of GLUT4 in gastrocnemius [27], or that it had no effects on GLUT4 protein level in hindlimb muscles of OVX rats [26].

Here, we have provided evidence for the first time that Ex training enhances basal levels of phosphorylated TBC1D1 $\mathrm{Ser}^{237}$, as well as GLUT4 protein, in the gastrocnemius muscle of OVX rats (18 h after final training session). Actually, TBC1D1 abundances did not differ from AS160 among multiple rat muscles with divergent fiber type profiles, including the soleus, EDL, and tibialis anterior muscles [19].

We did not clarify why GLUT4 protein was increased in the Pla/Ex group without increased mRNA levels. There is some controversy as to the mechanism for the Ex-induced increase of GLUT4 protein levels; however, the majority of studies reported increased GLUT4 protein levels rather than mRNA levels. Gurley et al. reported that voluntary wheel running Ex increased muscle GLUT4 protein levels and improved fasting plasma insulin, but did not increase muscle GLUT4 mRNA in high-fat diet-induced obese mice, suggesting that 
Fig. 5 The relative values of Akt substrate of $160 \mathrm{kDa}$ (AS160) (a) and GLUT4 (b) mRNA levels in the gastrocnemius, and AS160 mRNA levels in the mesenteric adipose tissue (c) of rats in the placebo (Pla, $n=6$ )-, the $17 \beta$-estradiol (E2, $n=6)$-treated, the placebo/ pair-feeding (Pla/PF, $n=6)$, and the placebo/exercise training $(\mathrm{Pla} / \mathrm{Ex}, n=6)$ groups. Data are evaluated as $2^{-\Delta \Delta C_{\mathrm{t}}}$ using $\beta-2 \mathrm{M}$ as a housekeeping gene and expressed as means \pm SE. One-way ANOVA followed by a post hoc Tukey's HSD test. $* * P<0.01$ and $* * * P<0.001$, difference between the two groups
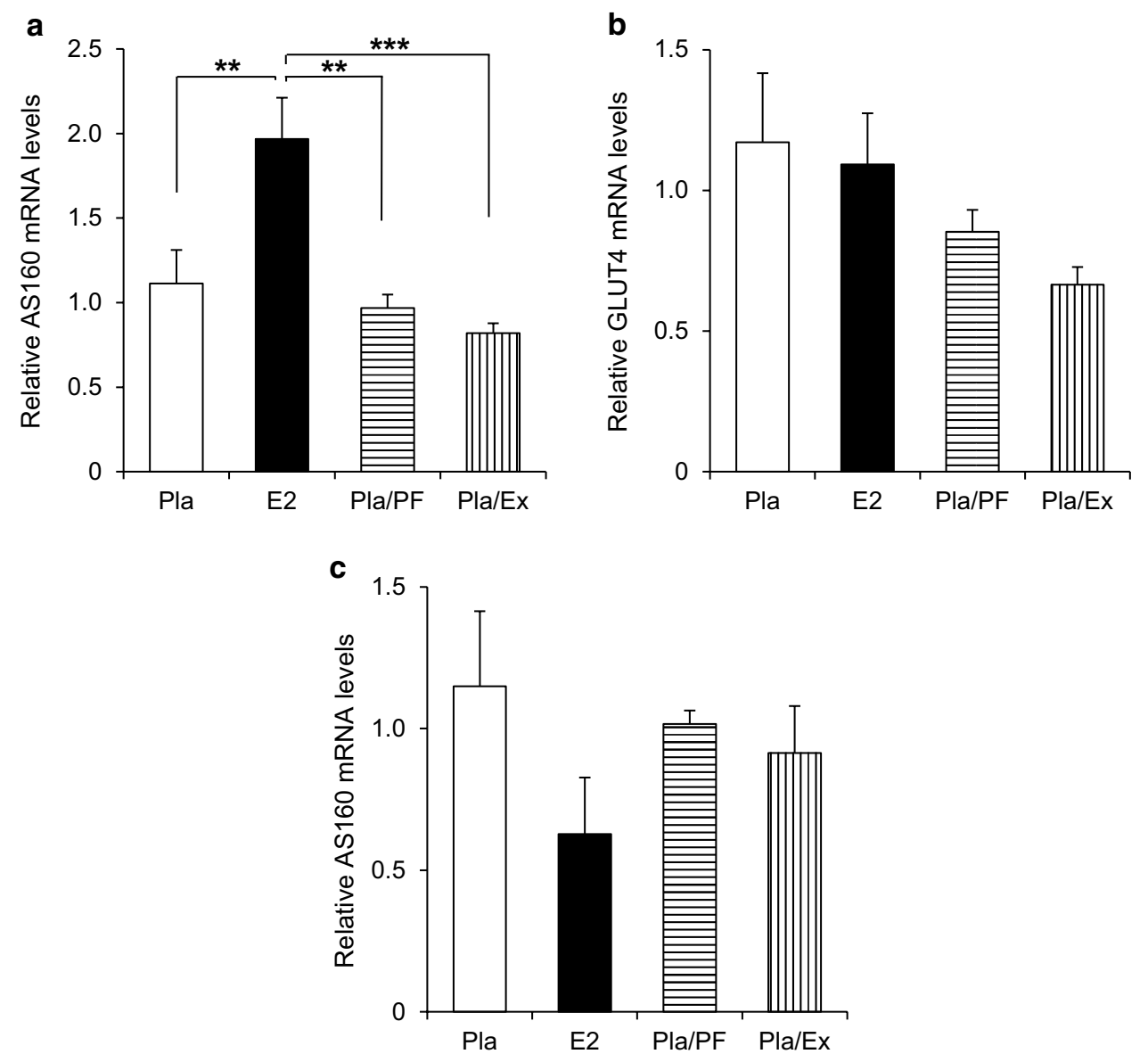

a post-transcriptional mechanism regulated muscle GLUT4 protein expression in response to Ex [49]. Similarly, a posttranscriptional mechanism might explain our results, showing an Ex training-induced increase in muscle GLUT4 protein expression in OVX rats. Our data suggest the E2 upregulates AS160 gene expressions most likely by the transcriptional activation function of estrogen receptor (ER) and at least partially by autoregulation of ER mRNA stabilities [50]. Taken together, the cellular mechanism underlying the beneficial effects of endurance Ex on the plasma glucose level might be distinct from that of E2 replacement.

In summary, this is a report showing endurance running Ex training which improves OVX-induced hyperglycemia and HOMA-IR, an indicator for insulin resistance, via activation of the TBC1D1/GLUT4 pathway in gastrocnemius by an alternative mechanism from action of E2 replacement or PF diet. Further study is required to identify the effects of endurance Ex training on insulin- and contraction-stimulated glucose uptake and signaling pathways, on the basis of comparison with the effects of E2 replacement. Our results provide insights into the alternative effects of endurance Ex training on glucose metabolism under reduced estrogen function in postmenopausal women.
Author contribution Concept/design: $\mathrm{KM}$ and MK; acquisition of data: $\mathrm{MK}, \mathrm{KM}$, and NY-N; data analysis and interpretation: KM and MK; drafting of the manuscript: KM, MK, and AT; critical revision of the manuscript: KM, MK, and AT; approval of the article: all authors.

Funding This study was funded by Grant-in-Aid for Scientific Research from Nara Women's University.

\section{Compliance with ethical standards}

Conflict of interest All authors declare that they have no conflict of interest.

Ethical approval All procedures performed in this study were in accordance with the guidelines on the use and care of laboratory animals as put forward by the Physiological Society of Japan and under the control of the Ethics Committee of Animal Care and Experimentation,

\section{References}

1. Carr MC (2003) The emergence of the metabolic syndrome with menopause. J Clin Endocrinol Metab 88:2404-2411

2. Park YW, Zhu S, Palaniappan L, Heshka S, Carnethon MR, Heymsfield SB (2003) The metabolic syndrome: prevalence and associated risk factor findings in the US population from the Third Nara Women's University, Japan. 
National Health and Nutrition Examination Survey, 1988-1994. Arch Intern Med 163:427-436

3. Lee CG, Carr MC, Murdoch SJ, Mitchell E, Woods NF, Wener MH, Chandler WL, Boyko EJ, Brunzell JD (2009) Adipokines, inflammation, and visceral adiposity across the menopausal transition: a prospective study. J Clin Endocrinol Metab 94:1104-1110

4. Tchernof A, Desmeules A, Richard C, Laberge P, Daris M, Mailloux J, Rhéaume C, Dupont P (2004) Ovarian hormone status and abdominal visceral adipose tissue metabolism. J Clin Endocrinol Metab 89:3425-3430

5. Richard D, Rochon L, Deshaies Y (1987) Effects of exercise training on energy balance of ovariectomized rats. Am J Physiol Regul Integr Comp Physiol 253:R740-R745

6. Zoth N, Weigt C, Laudenbach-Leschowski U, Diel P (2010) Physical activity and estrogen treatment reduce visceral body fat and serum levels of leptin in an additive manner in a diet induced animal model of obesity. J Steroid Biochem Mol Biol 122:100-105

7. Kawakami M, Yokota-Nakagi N, Uji M, Yoshida KI, Tazumi S, Takamata A, Uchida Y, Morimoto K (2018) Estrogen replacement enhances insulin-induced AS160 activation and improves insulin sensitivity in ovariectomized rats. Am J Physiol Endocrinol Metab 315:E1296-E1304

8. Després JP, Lemieux I (2006) Abdominal obesity and metabolic syndrome. Nature 444:881-887

9. Gower BA, Muñoz J, Desmond R, Hilario-Hailey T, Jiao X (2006) Changes in intra-abdominal fat in early postmenopausal women: effects of hormone use. Obesity 14:1046-1055

10. Sites CK, L'Hommedieu GD, Toth MJ, Brochu M, Cooper BC, Fairhurst PA (2005) The effect of hormone replacement therapy on body composition, body fat distribution, and insulin sensitivity in menopausal women: a randomized, double-blind, placebocontrolled trial. J Clin Endocrinol Metab 90:2701-2707

11. Spencer CP, Godsland IF, Cooper AJ, Ross D, Whitehead MI, Stevenson JC (2000) Effects of oral and transdermal 17 $\beta$-estradiol with cyclical oral norethindrone acetate on insulin sensitivity, secretion, and elimination in postmenopausal women. Metabolism 49:742-747

12. Soranna L, Cucinelli F, Perri C, Muzj G, Giuliani M, Villa P, Lanzone A (2002) Individual effect of E2 and dydrogesterone on insulin sensitivity in post-menopausal women. J Endocrinol Investig 25:547-550

13. Howard BV, Rossouw JE (2013) Estrogens and cardiovascular disease risk revisited: the Women's Health Initiative. Curr Opin Lipidol 24:493-499

14. Evans EM, Van Pelt RE, Binder EF, Williams DB, Ehsani AA, Kohrt WM (2001) Effects of HRT and exercise training on insulin action, glucose tolerance, and body composition in older women. J Appl Physiol 90:2033-2040

15. Brown MD, Korytkowski MT, Zmuda JM, McCole SD, Moore GE, Hagberg JM (2000) Insulin sensitivity in postmenopausal women: independent and combined associations with hormone replacement, cardiovascular fitness, and body composition. Diabetes Care 23:1731-1736

16. Latour MG, Shinoda M, Lavoie JM (2001) Metabolic effects of physical training in ovariectomized and hyperestrogenic rats. $\mathrm{J}$ Appl Physiol 90:235-241

17. Saengsirisuwan V, Pongseeda S, Prasannarong M, Vichaiwong K, Toskulkao C (2009) Modulation of insulin resistance in ovariectomized rats by endurance exercise training and estrogen replacement. Metabolism 58:38-47

18. DeFronzo RA, Jacot E, Jequier E, Maeder E, Wahren J, Felber JP (1981) The effect of insulin on the disposal of intravenous glucose. Results from indirect calorimetry and hepatic and femoral venous catheterization. Diabetes 30:1000-1007
19. Cartee GD (2015) Roles of TBC1D1 and TBC1D4 in insulin- and exercise-stimulated glucose transport of skeletal muscle. Diabetologia 58:19-30

20. Kramer HF, Witczak CA, Taylor EB, Fujii N, Hirshman MF, Goodyear LJ (2006) AS160 regulates insulin- and contractionstimulated glucose uptake in mouse skeletal muscle. J Biol Chem 281:31478-31485

21. Sakamoto K, Holman GD (2008) Emerging role for AS160/ TBC1D4 and TBC1D1 in the regulation of GLUT4 traffic. Am J Physiol Endocrinol Metab 295:E29-E37

22. Gonzalez E, McGraw TE (2006) Insulin signaling diverges into Akt-dependent and -independent signals to regulate the recruitment/docking and the fusion of GLUT4 vesicles to the plasma membrane. Mol Biol Cell 17:4484-4493

23. Lansey MN, Walker NN, Hargett SR, Stevens JR, Keller SR (2012) Deletion of Rab GAP AS160 modifies glucose uptake and GLUT4 translocation in primary skeletal muscles and adipocytes and impairs glucose homeostasis. Am J Physiol Endocrinol Metab 303:E1273-E1286

24. Friedrichsen M, Mortensen B, Pehmøller C, Birk JB, Wojtaszewski JF (2013) Exercise-induced AMPK activity in skeletal muscle: role in glucose uptake and insulin sensitivity. Mol Cell Endocrinol 366:204-214

25. Kramer HF, Witczak CA, Fujii N, Jessen N, Taylor EB, Arnolds DE, Sakamoto K, Hirshman MF, Goodyear LJ (2006) Distinct signals regulate AS160 phosphorylation in response to insulin, AICAR, and contraction in mouse skeletal muscle. Diabetes 55:2067-2076

26. MacDonald TL, Ritchie KL, Davies S, Hamilton MJ, Cervone DT, Dyck DJ (2015) Exercise training is an effective alternative to estrogen supplementation for improving glucose homeostasis in ovariectomized rats. Physiol Rep 3:e12617

27. Zoth N, Weigt C, Zengin S, Selder O, Selke N, Kalicinski M, Piechotta M, Diel P (2012) Metabolic effects of estrogen substitution in combination with targeted exercise training on the therapy of obesity in ovariectomized Wistar rats. J Steroid Biochem Mol Biol 130:64-72

28. Szmuilowicz ED, Stuenkel CA, Seely EW (2009) Influence of menopause on diabetes and diabetes risk. Nat Rev Endocrinol 5:553-558

29. Toth MJ, Sites CK, Eltabbakh GH, Poehlman ET (2000) Effect of menopausal status on insulin-stimulated glucose disposal: comparison of middle-aged premenopausal and early postmenopausal women. Diabetes Care 23:801-806

30. DeNino WF, Tchernof A, Dionne IJ, Toth MJ, Ades PA, Sites CK, Poehlman ET (2001) Contribution of abdominal adiposity to age-related differences in insulin sensitivity and plasma lipids in healthy nonobese women. Diabetes Care 24:925-932

31. Prasannarong M, Vichaiwong K, Saengsirisuwan V (2012) Calorie restriction prevents the development of insulin resistance and impaired insulin signaling in skeletal muscle of ovariectomized rats. Biochim Biophys Acta 1822:1051-1061

32. Tazumi S, Omoto S, Nagatomo Y, Kawahara M, Yokota-Nakagi N, Kawakami M, Takamata A, Morimoto K (2018) Estrogen replacement attenuates stress-induced pressor responses through vasorelaxation via $\beta_{2}$-adrenoceptors in peripheral arteries of ovariectomized rats. Am J Physiol Heart Circ Physiol 314:H213-H223

33. Morimoto K, Kurahashi Y, Shintani-Ishida K, Kawamura N, Miyashita M, Uji M, Tan N, Yoshida K (2004) Estrogen replacement suppresses stress-induced cardiovascular responses in ovariectomized rats. Am J Physiol Heart Circ Physiol 287:H1950-H1956

34. Patch LD, Brooks GA (1980) Effects of training on $\mathrm{VO}_{2} \max$ and $\mathrm{VO}_{2}$ during two running intensities in rats. Pflügers Arch $386: 215-219$ 
35. Mitchell TW, Turner N, Hulbert AJ, Else PL, Hawley JA, Lee JS, Bruce CR, Blanksby SJ (2004) Exercise alters the profile of phospholipid molecular species in rat skeletal muscle. J Appl Physiol 97:1823-1829

36. Torbati D, Ramirez J, Hon E, Camacho MT, Sussmane JB, Raszynski A, Wolfsdorf J (1999) Experimental critical care in rats: gender differences in anesthesia, ventilation, and gas exchange. Crit Care Med 27:1878-1884

37. Antunes LC, Elkfury JL, Jornada MN, Foletto KC, Bertoluci MC (2016) Validation of HOMA-IR in a model of insulin-resistance induced by a high-fat diet in Wistar rats. Arch Endocrinol Metab 60:138-142

38. Bonora E, Targher G, Alberiche M, Bonadonna RC, Saggiani F, Zenere MB, Monauni T, Muggeo M (2000) Homeostasis model assessment closely mirrors the glucose clamp technique in the assessment of insulin sensitivity: studies in subjects with various degrees of glucose tolerance and insulin sensitivity. Diabetes Care 23:57-63

39. Turner RC, Holman RR, Matthews D, Hockaday TD, Peto J (1979) Insulin deficiency and insulin resistance interaction in diabetes: estimation of their relative contribution by feedback analysis from basal plasma insulin and glucose concentrations. Metabolism 28:1086-1096

40. D'Eon TM, Souza SC, Aronovitz M, Obin MS, Fried SK, Greenberg AS (2005) Estrogen regulation of adiposity and fuel partitioning. Evidence of genomic and non-genomic regulation of lipogenic and oxidative pathways. J Biol Chem 280:35983-35991

41. Heine PA, Taylor JA, Iwamoto GA, Lubahn DB, Cooke PS (2000) Increased adipose tissue in male and female estrogen receptor- $\alpha$ knockout mice. Proc Natl Acad Sci USA 97:12729-12734

42. Weigt C, Hertrampf T, Flenker U, Hülsemann F, Kurnaz P, Fritzemeier KH, Diel P (2015) Effects of estradiol, estrogen receptor subtype-selective agonists and genistein on glucose metabolism in leptin resistant female Zucker diabetic fatty (ZDF) rats. J Steroid Biochem Mol Biol 154:12-22
43. Gao Q, Mezei G, Nie Y, Rao Y, Choi CS, Bechmann I, Leranth C, Toran-Allerand D, Priest CA, Roberts JL, Gao XB, Mobbs C, Shulman GI, Diano S, Horvath TL (2007) Anorectic estrogen mimics leptin's effect on the rewiring of melanocortin cells and Stat3 signaling in obese animals. Nat Med 13:89-94

44. Geary N, Asarian L, Korach KS, Pfaff DW, Ogawa S (2001) Deficits in E2-dependent control of feeding, weight gain, and cholecystokinin satiation in ER- $\alpha$ null mice. Endocrinology 142:4751-4757

45. Watanabe T, Morimoto A, Sakata Y, Tan N, Morimoto K, Murakami N (1992) Running training attenuates the ACTH responses in rats to swimming and cage-switch stress. J Appl Physiol 73:2452-2456

46. Butcher RL, Collins WE, Fugo NW (1974) Plasma concentration of LH, FSH, prolactin, progesterone and estradiol-17 $\beta$ throughout the 4-day estrous cycle of the rat. Endocrinology 94:1704-1708

47. Widdop RE, Denton KM (2012) The arterial depressor response to chronic low-dose angiotensin II infusion in female rats is estrogen dependent. Am J Physiol Regul Integr Comp Physiol 302:R159-R165

48. Cleary MP, Muller S, Lanza-Jacoby S (1987) Effects of longterm moderate food restriction on growth, serum factors, lipogenic enzymes and adipocyte glucose metabolism in lean and obese Zucker rats. J Nutr 117:355-360

49. Gurley JM, Griesel BA, Olson AL (2016) Increased skeletal muscle GLUT4 expression in obese mice after voluntary wheel running exercise is posttranscriptional. Diabetes 65:2911-2919

50. Ing NH (2005) Steroid hormones regulate gene expression posttranscriptionally by altering the stabilities of messenger RNAs. Biol Reprod 72:1290-1296

Publisher's Note Springer Nature remains neutral with regard to jurisdictional claims in published maps and institutional affiliations. 